\title{
Avaliação de habilidades matemáticas em crianças com síndrome de Down e com desenvolvimento típico
}

\author{
Mathematical skills assessment in children \\ with Downs syndrome and typical development
}

\begin{abstract}
Ailton Barcelos da Costa ${ }^{1}$. Alessandra Daniele Messali Picharillo ${ }^{2}$. Nassim Chamel Elias ${ }^{1}$
\end{abstract}

\begin{abstract}
Resumo: O conhecimento matemático é considerado fundamental para qualquer pessoa ter uma vida independente, sendo considerada uma disciplina de grande dificuldade de aprendizado, tanto por pessoas com desenvolvimento típico quanto por aquelas com deficiência intelectual. O presente estudo avaliou as habilidades matemáticas em 11 crianças com síndrome de Down (SD) e dez com desenvolvimento típico, com idade entre seis e dez anos, nos aspectos discretos e contínuos. Foi desenvolvido, em forma de protocolo, um procedimento de levantamento de habilidades matemáticas básicas, o qual foi aplicado, após sua criação, em forma de teste. Os resultados indicam o desempenho mais baixo dos participantes com SD em comparação com aqueles com desenvolvimento típico. Tal desempenho mais baixo pode estar ligado às dificuldades nas habilidades que requeiram atenção, memória, raciocínio e abstração, fundamentais para o aprendizado acadêmico em geral.
\end{abstract}

Palavras-chave: Deficiência intelectual. Habilidades. Educação matemática. Educação Infantil. Educação especial. Síndrome de Down.

\begin{abstract}
Mathematical knowledge is considered essential for anyone to have an independent life and is considered a discipline it is difficult to learn for both people with normal development, as well as those with intellectual disabilities. This study assessed the math skills of 11 children with Downs Syndrome (DS) and 10 typically developing young people, aged six and ten years both in discrete and continuous aspects. A survey procedure for basic math skills was developed and applied. There was the creation of the instrument in the form of a protocol, and a test. The results indicate the lowest performance of participants with Downs syndrome compared to those with typical development. Such lower performance can be linked to difficulties in skills requiring attention, memory, reasoning, and abstraction and are fundamental to academic learning in general.
\end{abstract}

Keywords: Intellectual Disability. Math Skills. Early Childhood Education. Special Education. Down's syndrome.

\footnotetext{
${ }^{1}$ Universidade Federal de São Carlos (UFSCar), Programa de Pós-graduação em Educação Especial, São Carlos, SP, Brasil. E-mail: <ailton_barcelos@yahoo.com.br>.

${ }^{2}$ Universidade Federal de São Carlos (UFSCar), São Carlos, SP, Brasil.
} 


\section{Introdução}

A competência em habilidades matemáticas é essencial para uma vida independente, principalmente nas atividades da idade adulta, pois indivíduos com sólida formação matemática podem resolver diversos problemas da vida diária (ROSENBLUM; HERZBERG, 2011). Entretanto, de $5 \%$ a $7 \%$ de toda a população mundial tem sérias dificuldades com o aprendizado dessas habilidades (BRANKAER; GHESQUIÈRE; DE SMEDT, 2013). No Brasil, os dados não são muito alentadores, já que $67,5 \%$ dos alunos da faixa etária de 10 anos ( $5^{\circ}$ ano do Ensino Fundamental) apresentam dificuldades na aprendizagem deste conteúdo (CRUZ; BERGAMASCHI; REIS, 2012).

Esses dados sugerem que a matemática é uma disciplina bastante complexa e de difícil aprendizado, devido, por exemplo, à grande abstração de seus conceitos, para qualquer pessoa, principalmente para pessoas com capacidade intelectual abaixo da média (BRANKAER; GHESQUIÈRE; DE SMEDT, 2013). Apesar das dificuldades apresentadas por essas pessoas, isso não significa que elas são incapazes de aprender matemática (CARMO, 2012).

Nesse sentido, Carmo (2012) enumera as habilidades matemáticas básicas que podem fazer parte de uma programação de ensino de matemática para indivíduos com deficiência intelectual, partindo de unidades menores que facilitem a aprendizagem de repertórios simples e, progressivamente, vão se tornando mais complexas. Entre as habilidades descritas, destacam-se as habilidades pré-numéricas, conceito de número, produção de sequências, união, separação e identificação de conjuntos e subconjuntos e contagem.

A deficiência intelectual, de acordo com o DSM-5 (AMERICAN PSYCHIATRIC ASSOCIATION, 2013), é caracterizada por déficit de habilidades mentais gerais, como raciocínio, resolução de problemas, planejamento, pensamento abstrato, julgamento, aprendizagem escolar e aprendizagem a partir da experiência.

Dentre as populações que apresentam deficiência intelectual, podem-se destacar as pessoas com síndrome de Down (SD), ou trissomia do 21, que é uma condição humana geneticamente determinada por alteração cromossômica, sendo essa a principal causa de deficiência intelectual na população (BRASIL, 2012).

Para Chung e Tam (2005) e Malaquias et al. (2013), alunos com deficiência intelectual, e em especial aqueles com SD, apresentam dificuldades em habilidades que são fundamentais para o aprendizado acadêmico em geral, como:

- Habilidades de percepção, como relações espaciais, distâncias e sequenciamento, que podem interferir na aquisição de conceitos e habilidades matemáticas;

- Pensamento e raciocínio, levando a dificuldades na resolução de problemas;

- Memória, dificultando que esses alunos se lembrem de informações anteriores, como os símbolos abstratos usados em matemática (menos, maior que, menor que, etc.);

- Generalização, dificultando o uso de conceitos aprendidos em um novo contexto;

- Atenção e concentração, necessários em situações de aprendizagem formal;

. Motivação, sendo que alguns destes alunos não se sentem motivados espontaneamente, exigindo a mediação do professor para se envolverem com as atividades, principalmente as que apresentam um maior nível de dificuldade e que não têm uma função social imediata e clara. 
Para Abdelahmeed (2007), pessoas com SD variam muito em suas conquistas e interesses em habilidades numéricas, existindo pouca quantidade de pesquisas na área no que se refere à orientação para os métodos e materiais de ensino eficazes, estando estes em um nível mais baixo em suas realizações do que seus pares com desenvolvimento típico. $\mathrm{O}$ autor ainda afirma que, quando um aluno com síndrome de Down está interessado e motivado, ele pode atingir um nível adequado no desenvolvimento destas habilidades ainda na escola primária. Resultados de pesquisas indicam que o bom ensino, utilizando os pontos fortes das crianças para a aprendizagem visual e materiais que exploram o tato e a visão, pode promover a aprendizagem de crianças com SD em estágios semelhantes aos das crianças com desenvolvimento típico, embora muitas vezes com mais etapas e mais exercícios (ABDELAHMEED, 2007).

Cornwell (1974) afirma que pessoas com SD, com ou sem linguagem expressiva, têm dificuldades em lidar com símbolos numéricos e em adquirir o conceito de número, justamente devido ao déficit na sua linguagem expressiva, déficit auditivo ou sua memória de curto prazo. Por sua vez, Abdelahmeed (2007) diz que existem enormes variações entre as crianças com SD, e que tais crianças podem sentir dificuldade em contar por causa de um déficit de linguagem e memória. Nessa mesma linha, Oliver e Buckley (1994) indicaram que existe uma grande diferença individual na aquisição de linguagem em crianças com SD e que o desenvolvimento de sua linguagem pode avançar em um ritmo mais lento do que em crianças com desenvolvimento típico.

Abdelahmeed (2007), ao fazer uma revisão da literatura para identificar e analisar a capacidade de contar de crianças com SD, afirma que estas crianças se beneficiam de intervenções que utilizam atividades de ensino e jogos com dados, sempre com mediação de um professor. Esse autor também diz que entre os erros mais cometidos pelas crianças com SD no processo de contagem, estão: a criança erra a sequência de palavras-número; as crianças apontam um objeto, mas não associam nenhuma palavra-número; e apontam um objeto e associam mais de uma palavra-número.

Outras pesquisas investigaram a aquisição de habilidades matemáticas em pessoas com SD e deficiência intelectual. Rossit (2003) teve por objetivo desenvolver e avaliar um currículo baseado no paradigma de equivalência de estímulos para ensinar 11 participantes com deficiência intelectual e idades entre nove e 32 a manusear dinheiro. A autora iniciou a pesquisa com uma avaliação de comportamentos matemáticos básicos presentes no repertório de cada participante, feita por meio da aplicação de alguns testes com materiais concretos. O estudo testou as relações referentes a comportamentos de contagem, numerosidade, noção de quantidade (maior, menor e igual), nomeação e identificação de valores monetários, usando palavras ditadas, numerais impressos, figuras de moedas e notas, numerais intercalados com sinais da adição, conjunto de moedas, notas e moedas juntas, preços impressos, moedas e notas verdadeiras. Os resultados indicaram que quatro participantes apresentaram desempenhos altos nas relações testadas; dois apresentaram desempenhos medianos, enquanto cinco demonstraram desempenhos inferiores na realização das tarefas. Os resultados demonstraram a eficácia do currículo informatizado sugerido pela autora e dos procedimentos de ensino utilizados, constatando a aquisição de uma ampla e complexa rede de relações matemáticas ensinada a partir do treino direto de apenas algumas dessas relações.

Yokoyama (2012) analisou as práticas de oito pessoas com SD, com idades entre cinco e 19 anos, com relação aos conceitos de número natural, para determinar a capacidade de quantificação de um conjunto qualquer, usando como método design experiments, que tem 
como principal característica o intervencionismo (dentro de um determinado ambiente educativo, a interação e a criação de teorias de ensino e aprendizagem). $\mathrm{O}$ autor realizou a pesquisa em duas fases: na primeira, o foco foi a construção de atividades de ensino que, aplicadas aos participantes, permitiu um ajuste do procedimento; na segunda fase, o autor aplicou as atividades a três participantes, com idades entre 12 e 19 anos. Os resultados de Yokoyama (2012) indicaram que os três participantes melhoraram sua capacidade de quantificar conjuntos discretos de objetos. Outro aspecto importante foi a utilização de recursos multissensoriais, para permitir que os participantes fossem além da utilização de procedimentos de contagem mecanizada (YOKOYAMA, 2012).

Rietveld (2005) investigou o processo de aprendizagem matemática em três meninos com SD entre cinco e seis anos, por meio da observação direta do comportamento deles em turmas regulares, com 26 crianças com desenvolvimento típico. Como resultado, percebeu-se que as crianças não compreendiam bem alguns conceitos básicos, como o princípio da contagem. Notou-se que barreiras de aprendizagem foram evidentes em todos os contextos, pois os professores não tinham estabelecido os conceitos fundamentais para o ensino da matemática antes de se iniciarem as atividades de ensino na sala de aula.

Brankaer, Ghesquière e De Smedt (2011) investigaram o processamento de magnitude numérica (comparação de grandezas) em crianças com deficiência intelectual leve. Os autores fizeram a comparação do desempenho de 26 crianças deste perfil, com o desempenho de dois grupos controle de crianças com desenvolvimento típico, um grupo com idade cronológica equivalente ao experimental e um grupo de correspondentes de acordo com as habilidades matemáticas. Os resultados revelaram que as crianças com deficiência intelectual leve tiveram pior desempenho do que os seus pares com desenvolvimento típico de mesma idade cronológica em ambas as tarefas, indicando que elas têm problemas na compreensão dos símbolos numéricos.

Dificuldades no aprendizado de determinadas habilidades matemáticas também foram identificadas em crianças com desenvolvimento típico. Zhou, Peverly e Lin (2005) aplicaram uma gama de tarefas para levantamento de repertório matemático em 160 crianças na faixa dos seis anos de idade, na China e nos EUA, avaliando identificação de formas geométricas, resolução de problemas e raciocínio lógico, bem como operações com números, para determinar se existem diferenças entre cultura no desenvolvimento do conhecimento matemático em todos os domínios e se a taxa ou ordem de desenvolvimento das habilidades matemáticas é comparável entre as culturas. Os resultados indicaram que as crianças chinesas superaram as crianças americanas em quase todas as tarefas. Os autores ressaltam que a dificuldade em conceitos de matemática parece ser universal. Importante ressaltar que Zhou, Peverly e Lin (2005) trabalharam com aspectos discretos (como contagem, aritmética e numeração) e contínuos (como geometria plana e espacial) da matemática.

Gualberto, Aloi e Carmo (2012) desenvolveram e aplicaram um instrumento de avaliação matemática que contemplava habilidades pré-aritméticas, apontadas como relevantes em crianças das primeiras séries do Ensino Fundamental. Participaram três crianças do Ensino Fundamental da rede municipal de ensino de São Carlos, SP. Foi aplicada uma bateria de testes com dez tarefas que envolviam as habilidades de sequenciação de numerais, classificação de figuras, conjuntos, igualdade entre quantidades e entre conjuntos, contagem e ordenação, usando o procedimento de escolha de acordo com o modelo. Os resultados indicaram desempenhos entre $73 \%$ e 97\% de acertos nas tarefas. Tarefas que exigiam produção de sequências, com ou sem discriminação 
de quantidade, representaram maior dificuldade para os participantes, mostrando-se eficaz para a descrição do repertório inicial dos participantes. Este estudo mostrou-se eficiente para o levantamento de habilidades matemáticas para crianças com desenvolvimento típico.

Dessa forma, pode-se notar que os estudos anteriores apontam que pessoas, com ou sem deficiência intelectual, apresentam alguma dificuldade no aprendizado de determinadas habilidades matemáticas. Entretanto, nenhum estudo avaliou e comparou, ao mesmo tempo, habilidades matemáticas básicas, referentes aos conceitos de contagem e medida, entre crianças com deficiência intelectual e com desenvolvimento típico, parecendo ser relevante investigar se as diferenças no desempenho das habilidades matemáticas de crianças com síndrome de Down e com desenvolvimento típico se dão tanto para os conceitos de contagem como para medida.

\section{Objetivos}

Avaliar o repertório das habilidades matemáticas de crianças com síndrome de Down e com desenvolvimento típico nos conceitos de contagem e medida.

Testar a aplicabilidade de um protocolo de avaliação de habilidades desenvolvidos pelos autores com crianças com SD e com desenvolvimento típico.

\section{Método}

\section{Materiais e equipamentos}

Os materiais e equipamentos utilizados foram fichas de papelão com numerais, figuras geométricas bidimensionais (quadrados, círculos e triângulos) em EVA, Brinquedo Monta Fácil ${ }^{3}$ e barbante, além de papel e caneta.

\section{Participantes}

Participaram da pesquisa 11 crianças com síndrome de Down e dez crianças com desenvolvimento típico, com idades entre cinco e dez anos.

Os critérios de inclusão de crianças com desenvolvimento típico na pesquisa foram: (a) que elas estivessem frequentando a escola regular; e (b) tivessem entre cinco e dez anos de idade; ou seja, para Brasil (2013), estas crianças estariam frequentando a Alfabetização e/ou Ensino Fundamental 1 (de $1^{\circ}$ a $5^{\circ}$ ano). Foram recrutadas crianças do convívio dos pesquisadores.

Para as crianças com síndrome de Down, o critério foi que elas tivessem entre cinco e dez anos de idade, além de terem diagnóstico de síndrome de Down informado pelo responsável ou instituição. Três delas foram recrutadas durante sua participação no "Grupo de Orientação e

\footnotetext{
${ }^{3}$ São blocos de encaixar, com peças em formas de quadrados, de retângulos, triângulos e setores circulares, de material plástico.
} 
Costa, A. B.; Picharillo, A. D. M.; Elias, N. C.

Informação - Avança Down", que ocorreu no câmpus de São Carlos da Universidade Federal de São Carlos (UFSCar), durante o ano de 2014, que tinha por objetivo levar informações e palestras para famílias de crianças com síndrome de Down, enquanto estas participavam de atividades pedagógicas e de recreação. As outras oito crianças foram recrutadas em uma instituição especializada, localizada em uma cidade de médio porte do interior do Estado de São Paulo, no mês de março de 2015.

O Quadro 1 apresenta as características de cada participante e o código para representar cada um deles, sendo que a letra $\mathrm{S}$ representa síndrome de Down e a letra T representa Desenvolvimento Típico.

Quadro 1. Características dos participantes

\begin{tabular}{|c|c|c|c|}
\hline Participante & Idade (anos) & Gênero & Diagnóstico informado \\
\hline P1S & 8 & Feminino & S. de Down \\
\hline P2S & 7 & Masculino & S. de Down \\
\hline P3S & 9 & Masculino & S. de Down \\
\hline P4S & 6 & Masculino & S. de Down \\
\hline P5S & 6 & Masculino & S. de Down \\
\hline P6S & 10 & Feminino & S. de Down \\
\hline P7S & 10 & Masculino & S. de Down \\
\hline P8S & 8 & Feminino & S. de Down \\
\hline P9S & 5 & Feminino & S. de Down \\
\hline P10S & 6 & Feminino & S. de Down \\
\hline P11S & 10 & Masculino & S. de Down \\
\hline $\mathrm{P} 1 \mathrm{~T}$ & 6 & Feminino & Típico \\
\hline $\mathrm{P} 2 \mathrm{~T}$ & 5 & Feminino & Típico \\
\hline P3T & 10 & Feminino & Típico \\
\hline $\mathrm{P} 4 \mathrm{~T}$ & 9 & Feminino & Típico \\
\hline P5T & 9 & Feminino & Típico \\
\hline P6T & 6 & Feminino & Típico \\
\hline P7T & 10 & Feminino & Típico \\
\hline P8T & 8 & Masculino & Típico \\
\hline Р9Т & 8 & Masculino & Típico \\
\hline P10T & 7 & Feminino & Típico \\
\hline
\end{tabular}

Fonte: Elaborado pelos autores.

Após a aprovação da pesquisa no Conselho de Ética em Seres Humanos da UFSCar, com o parecer número $748.778 / 2014$, todos os procedimentos éticos foram tomados, com a 
assinatura do Termo de Consentimento Livre e Esclarecido pelos pais ou responsáveis, e do Termo de Assentimento pelos participantes.

\section{Procedimentos}

Foi aplicado o Protocolo de Registro e Avaliação das Habilidades Matemáticas (PRAHM), criado pelos pesquisadores a partir de uma compilação dos testes utilizados por Gualberto, Aloi e Carmo (2012), Zhou, Peverly e Lin (2005), Rossit (2003), Murphy (2009) e Carmo (2012), conforme observa-se no Quadro 2.

Quadro 2. Protocolo de Registro e Avaliação das Habilidades Matemáticas (PRAHM)

\begin{tabular}{|c|c|c|c|c|}
\hline \multicolumn{5}{|c|}{$\begin{array}{l}\text { Nome do aluno: } \\
\text { Data de Nascimento (dia/mês/ano): } \\
\text { Escola/Instituição: } \\
\text { Diagnóstico (se houver): } \\
\text { Data (dia/mês/ano): } \\
\text { Nome do Aplicador: } \\
\text { Início (hora/minuto): __ Término (hora/min }\end{array}$} \\
\hline \multicolumn{2}{|c|}{ Habilidade } & Arranjo de Materiais & Instrução & Respostas \\
\hline 1 & Contar até 10 & & Conte até 10. & $\begin{array}{l}\text { Recitar o nome dos } \\
\text { numerais em sequência }\end{array}$ \\
\hline 2 & $\begin{array}{l}\text { Contar número de } \\
\text { fichas }\end{array}$ & $\begin{array}{l}\text { Colocar } 4 \text { fichas sobre } \\
\text { a mesa. }\end{array}$ & $\begin{array}{l}\text { Conte quantas fichas } \\
\text { têm aqui. }\end{array}$ & Dizer "4" \\
\hline 3 & $\begin{array}{l}\text { Contar número de } \\
\text { fichas }\end{array}$ & $\begin{array}{l}\text { Colocar } 7 \text { fichas sobre } \\
\text { a mesa. }\end{array}$ & $\begin{array}{l}\text { Conte quantas fichas } \\
\text { têm aqui. }\end{array}$ & Dizer "7”" \\
\hline 4 & $\begin{array}{l}\text { Contar número de } \\
\text { fichas }\end{array}$ & $\begin{array}{l}\text { Colocar } 3 \text { fichas sobre } \\
\text { a mesa. }\end{array}$ & $\begin{array}{l}\text { Conte quantas fichas } \\
\text { têm aqui. }\end{array}$ & Dizer “3” \\
\hline 5 & $\begin{array}{l}\text { Ler um número } \\
\text { impresso e dizer } \\
\text { o que vem na } \\
\text { sequência }\end{array}$ & $\begin{array}{l}\text { Colocar um cartão com } \\
\text { o numeral } 2 \text { impresso } \\
\text { sobre a mesa. }\end{array}$ & $\begin{array}{l}\text { Esse é o (completar) } \\
\text { e depois vem o } \\
\text { (completar). }\end{array}$ & Dizer "2” ... "3” \\
\hline 6 & $\begin{array}{l}\text { Ler um número } \\
\text { impresso e dizer } \\
\text { o que vem na } \\
\text { sequência }\end{array}$ & $\begin{array}{l}\text { Colocar um cartão com } \\
\text { o numeral } 8 \text { impresso } \\
\text { sobre a mesa. }\end{array}$ & $\begin{array}{l}\text { Esse é o (completar) } \\
\text { e depois vem o } \\
\text { (completar). }\end{array}$ & Dizer “8”... “9”" \\
\hline 7 & $\begin{array}{l}\text { Ler um número } \\
\text { impresso e dizer } \\
\text { o que vem na } \\
\text { sequência }\end{array}$ & $\begin{array}{l}\text { Colocar um cartão com } \\
\text { o numeral } 5 \text { impresso } \\
\text { sobre a mesa. }\end{array}$ & $\begin{array}{l}\text { Esse é o (completar) } \\
\text { e depois vem o } \\
\text { (completar). }\end{array}$ & Dizer "5" ... "6" \\
\hline 8 & $\begin{array}{l}\text { Selecionar número } \\
\text { de fichas }\end{array}$ & $\begin{array}{l}\text { Colocar } 10 \text { fichas sobre } \\
\text { a mesa. }\end{array}$ & $\begin{array}{l}\text { Pegue } 5 \text { fichas e } \\
\text { coloque na minha } \\
\text { mão. }\end{array}$ & $\begin{array}{l}\text { Pegar } 5 \text { fichas e } \\
\text { entregar para o } \\
\text { instrutor }\end{array}$ \\
\hline
\end{tabular}


Quadro 2. continuação

\begin{tabular}{|c|c|c|c|c|}
\hline 9 & $\begin{array}{l}\text { Selecionar número } \\
\text { de fichas }\end{array}$ & $\begin{array}{l}\text { Colocar } 10 \text { fichas sobre } \\
\text { a mesa. }\end{array}$ & $\begin{array}{l}\text { Pegue } 2 \text { fichas e } \\
\text { coloque na minha } \\
\text { mão. }\end{array}$ & $\begin{array}{l}\text { Pegar } 2 \text { fichas e } \\
\text { entregar para o } \\
\text { instrutor }\end{array}$ \\
\hline 10 & $\begin{array}{l}\text { Selecionar número } \\
\text { de fichas }\end{array}$ & $\begin{array}{l}\text { Colocar } 10 \text { fichas sobre } \\
\text { a mesa. }\end{array}$ & $\begin{array}{l}\text { Pegue } 8 \text { fichas e } \\
\text { coloque na minha } \\
\text { mão. }\end{array}$ & $\begin{array}{l}\text { Pegar } 8 \text { fichas e } \\
\text { entregar para o } \\
\text { instrutor }\end{array}$ \\
\hline 11 & $\begin{array}{l}\text { Comparar } \\
\text { objetos unitários } \\
\text { (tridimensionais) }\end{array}$ & $\begin{array}{l}\text { Colocar três objetos } \\
\text { distintos sobre a mesa }\end{array}$ & Qual é o maior? & $\begin{array}{l}\text { Apontar para o objeto } \\
\text { com maior dimensão }\end{array}$ \\
\hline 12 & $\begin{array}{l}\text { Comparar } \\
\text { objetos unitários } \\
\text { (tridimensionais) } \\
\end{array}$ & $\begin{array}{l}\text { Colocar três objetos } \\
\text { distintos sobre a mesa }\end{array}$ & Qual é o menor? & $\begin{array}{l}\text { Apontar para o objeto } \\
\text { com menor dimensão }\end{array}$ \\
\hline 13 & $\begin{array}{l}\text { Comparar } \\
\text { objetos unitários } \\
\text { (tridimensionais) }\end{array}$ & $\begin{array}{l}\text { Colocar dois objetos } \\
\text { iguais e um distinto } \\
\text { sobre a mesa }\end{array}$ & Quais são iguais? & $\begin{array}{l}\text { Apontar para os dois } \\
\text { objetos com mesma } \\
\text { dimensão }\end{array}$ \\
\hline 14 & $\begin{array}{l}\text { Comparar o } \\
\text { tamanho de formas } \\
\text { geométricas } \\
\text { bidimensionais }\end{array}$ & $\begin{array}{l}\text { Colocar três quadrados } \\
\text { de tamanhos distintos }\end{array}$ & $\begin{array}{l}\text { Qual o quadrado } \\
\text { maior? }\end{array}$ & $\begin{array}{l}\text { Apontar para o } \\
\text { quadrado com maior } \\
\text { dimensão }\end{array}$ \\
\hline 15 & $\begin{array}{l}\text { Comparar o } \\
\text { tamanho de formas } \\
\text { geométricas } \\
\text { bidimensionais }\end{array}$ & $\begin{array}{l}\text { Colocar três círculos de } \\
\text { tamanhos distintos }\end{array}$ & $\begin{array}{l}\text { Qual o círculo } \\
\text { menor? }\end{array}$ & $\begin{array}{l}\text { Apontar para o círculo } \\
\text { com menor dimensão }\end{array}$ \\
\hline 16 & $\begin{array}{l}\text { Comparar o } \\
\text { tamanho de formas } \\
\text { geométricas } \\
\text { bidimensionais }\end{array}$ & $\begin{array}{l}\text { Colocar três triângulos, } \\
\text { sendo dois iguais e um } \\
\text { maior }\end{array}$ & $\begin{array}{l}\text { Quais os triângulos } \\
\text { iguais? }\end{array}$ & $\begin{array}{l}\text { Apontar para os dois } \\
\text { triângulos com mesma } \\
\text { dimensão }\end{array}$ \\
\hline 17 & $\begin{array}{l}\text { Comparar } \\
\text { quantidades de } \\
\text { objetos }\end{array}$ & $\begin{array}{l}\text { Colocar um conjunto } \\
\text { com quatro e outro } \\
\text { com sete objetos sobre } \\
\text { a mesa }\end{array}$ & Onde tem mais? & $\begin{array}{l}\text { Apontar para o } \\
\text { conjunto com sete } \\
\text { objetos }\end{array}$ \\
\hline 18 & $\begin{array}{l}\text { Comparar } \\
\text { quantidades de } \\
\text { objetos }\end{array}$ & $\begin{array}{l}\text { Colocar um conjunto } \\
\text { com sete e outro com } \\
\text { oito objetos sobre a } \\
\text { mesa }\end{array}$ & Onde tem menos? & $\begin{array}{l}\text { Apontar para o } \\
\text { conjunto com sete } \\
\text { objetos }\end{array}$ \\
\hline 19 & $\begin{array}{l}\text { Comparar } \\
\text { quantidades de } \\
\text { objetos }\end{array}$ & $\begin{array}{l}\text { Colocar um conjunto } \\
\text { com cinco e outro com } \\
\text { seis objetos sobre a } \\
\text { mesa }\end{array}$ & Onde tem mais? & $\begin{array}{l}\text { Apontar para o } \\
\text { conjunto com seis } \\
\text { objetos }\end{array}$ \\
\hline 20 & $\begin{array}{l}\text { Comparar } \\
\text { tamanhos } \\
\text { de objetos } \\
\text { unidimensionais }\end{array}$ & $\begin{array}{l}\text { Colocar uma fileira } \\
\text { com cinco blocos } \\
\text { retangulares encaixados } \\
\text { do brinquedo "Monta } \\
\text { Fácil" e outro com seis }\end{array}$ & $\begin{array}{l}\text { Qual desses é o } \\
\text { maior? }\end{array}$ & $\begin{array}{l}\text { Apontar para a fileira } \\
\text { com seis blocos }\end{array}$ \\
\hline
\end{tabular}


Quadro 2. continuação

\begin{tabular}{|c|c|c|c|c|}
\hline 21 & $\begin{array}{l}\text { Comparar } \\
\text { tamanhos } \\
\text { de objetos } \\
\text { unidimensionais }\end{array}$ & $\begin{array}{l}\text { Colocar uma fileira } \\
\text { com oito blocos } \\
\text { retangulares encaixados } \\
\text { do brinquedo "Monta } \\
\text { Fácil" e outro com } \\
\text { quatro }\end{array}$ & $\begin{array}{l}\text { Qual desses é o } \\
\text { menor? }\end{array}$ & $\begin{array}{l}\text { Apontar para a fileira } \\
\text { com quatro blocos }\end{array}$ \\
\hline 22 & $\begin{array}{l}\text { Comparar } \\
\text { tamanhos } \\
\text { de objetos } \\
\text { unidimensionais }\end{array}$ & $\begin{array}{l}\text { Colocar uma fileira } \\
\text { com três blocos } \\
\text { retangulares encaixados } \\
\text { do brinquedo "Monta } \\
\text { Fácil" e outro com } \\
\text { cinco }\end{array}$ & $\begin{array}{l}\text { Qual desses é o } \\
\text { maior? }\end{array}$ & $\begin{array}{l}\text { Apontar para a fileira } \\
\text { com cinco blocos }\end{array}$ \\
\hline 23 & $\begin{array}{l}\text { Comparar } \\
\text { quantidades de } \\
\text { forma visual }\end{array}$ & $\begin{array}{l}\text { Apresentar dois } \\
\text { cartões com bolinhas } \\
\text { desenhadas: um com } \\
\text { cinco bolinhas e outro } \\
\text { com seis }\end{array}$ & $\begin{array}{l}\text { Qual tem mais } \\
\text { bolinhas? }\end{array}$ & $\begin{array}{l}\text { Apontar para o cartão } \\
\text { com seis bolinhas }\end{array}$ \\
\hline 24 & $\begin{array}{l}\text { Comparar } \\
\text { quantidades de } \\
\text { forma visual }\end{array}$ & $\begin{array}{l}\text { Apresentar dois } \\
\text { cartões com bolinhas } \\
\text { desenhadas: um com } \\
\text { seis bolinhas e outro } \\
\text { com oito }\end{array}$ & $\begin{array}{l}\text { Qual tem mais } \\
\text { bolinhas? }\end{array}$ & $\begin{array}{l}\text { Apontar para o cartão } \\
\text { com oito bolinhas }\end{array}$ \\
\hline 25 & $\begin{array}{l}\text { Comparar } \\
\text { quantidades de } \\
\text { forma visual }\end{array}$ & $\begin{array}{l}\text { Apresentar dois } \\
\text { cartões com bolinhas } \\
\text { desenhadas: um com } \\
\text { três bolinhas e outro } \\
\text { com cinco }\end{array}$ & $\begin{array}{l}\text { Qual tem menos } \\
\text { bolinhas? }\end{array}$ & $\begin{array}{l}\text { Apontar para o cartão } \\
\text { com três bolinhas }\end{array}$ \\
\hline 26 & $\begin{array}{l}\text { Comparar } \\
\text { quantidades ditadas }\end{array}$ & & $\begin{array}{l}\text { Se você tem } 6 \text { fichas } \\
\text { e eu tenho } 5 \text {, quem } \\
\text { tem menos? }\end{array}$ & Dizer "Você" \\
\hline 27 & $\begin{array}{l}\text { Comparar } \\
\text { quantidades ditadas }\end{array}$ & & $\begin{array}{l}\text { Se você tem } 4 \text { fichas } \\
\text { e eu tenho } 7 \text {, quem } \\
\text { tem menos? }\end{array}$ & Dizer "Eu" \\
\hline 28 & $\begin{array}{l}\text { Comparar } \\
\text { quantidades ditadas }\end{array}$ & & $\begin{array}{l}\text { Se você tem } 8 \text { fichas } \\
\text { e eu tenho } 3 \text {, quem } \\
\text { tem menos? }\end{array}$ & Dizer "Você" \\
\hline 29 & $\begin{array}{l}\text { Comparar } \\
\text { quantidades de } \\
\text { forma visual }\end{array}$ & $\begin{array}{l}\text { Apresentar três } \\
\text { cartões com bolinhas } \\
\text { desenhadas, um ao } \\
\text { lado do outro, com as } \\
\text { quantidades: } 3,1,3 \\
\end{array}$ & $\begin{array}{l}\text { Pegue os dois cartões } \\
\text { iguais. }\end{array}$ & $\begin{array}{l}\text { Pegar os dois cartões } \\
\text { com } 3 \text { bolinhas }\end{array}$ \\
\hline
\end{tabular}


Quadro 2. continuação

\begin{tabular}{|l|l|l|l|l|}
\hline 30 & $\begin{array}{l}\text { Comparar } \\
\text { quantidades de } \\
\text { forma visual }\end{array}$ & $\begin{array}{l}\text { Apresentar três } \\
\text { cartões com bolinhas } \\
\text { desenhadas, um ao } \\
\text { lado do outro, com as } \\
\text { quantidades: 6, 6, 3 }\end{array}$ & $\begin{array}{l}\text { Pegue os dois cartões } \\
\text { iguais. }\end{array}$ & $\begin{array}{l}\text { Pegar os dois cartões } \\
\text { com 6 bolinhas }\end{array}$ \\
\hline 31 & $\begin{array}{l}\text { Comparar } \\
\text { quantidades de } \\
\text { forma visual }\end{array}$ & $\begin{array}{l}\text { Apresentar três } \\
\text { cartões com bolinhas } \\
\text { desenhadas, um ao } \\
\text { lado do outro, com as } \\
\text { quantidades: 4, 4, 6 }\end{array}$ & $\begin{array}{l}\text { Pegue os dois cartões } \\
\text { iguais }\end{array}$ & $\begin{array}{l}\text { Pegar os dois cartões } \\
\text { com 4 bolinhas }\end{array}$ \\
\hline 32 & $\begin{array}{l}\text { Nomear figuras } \\
\text { geométricas } \\
\text { bidimensionais }\end{array}$ & $\begin{array}{l}\text { Colocar um quadrado } \\
\text { sobre a mesa }\end{array}$ & $\begin{array}{l}\text { Qual o nome dessa } \\
\text { figura? }\end{array}$ & Dizer "Quadrado" \\
\hline 33 & $\begin{array}{l}\text { Nomear figuras } \\
\text { geométricas } \\
\text { bidimensionais }\end{array}$ & $\begin{array}{l}\text { Colocar um círculo } \\
\text { sobre a mesa }\end{array}$ & $\begin{array}{l}\text { Qual o nome dessa } \\
\text { figura? }\end{array}$ & Dizer "Círculo" \\
\hline 34 & $\begin{array}{l}\text { Nomear figuras } \\
\text { geométricas } \\
\text { bidimensionais }\end{array}$ & $\begin{array}{l}\text { Colocar um triângulo } \\
\text { sobre a mesa }\end{array}$ & $\begin{array}{l}\text { Qual o nome dessa } \\
\text { figura? }\end{array}$ & Dizer "Triângulo" \\
\hline
\end{tabular}

Fonte: Elaborado pelos autores.

O Protocolo contém 34 atividades de simples resolução, dividido em unidades curriculares de ensino que, para Carmo (2012), referem-se às etapas de aquisição de conceitos e habilidades matemáticas básicas e que podem fazer parte de uma programação de ensino de matemática para indivíduos com Deficiência Intelectual.

A divisão das questões em unidades curriculares de ensino é feita da seguinte forma:

- Nas questões 1, 2, 3, 4, 8, 9, e 10 são trabalhadas habilidades de contagem;

- Nas questões 5, 6 e 7 é trabalhada a produção de sequência;

- Nas questões de 11 a 31 são trabalhadas habilidades pré-aritméticas (maior/ menor/ igual e mais/ menos), divididas da seguinte forma:

- Usando objetos tridimensionais: $11,12,13$;

- Usando objetos bidimensionais: $14,15,16$;

- Usando objetos unidimensionais: 20,21, 22;

- Usando conjuntos de objetos tridimensionais: $17,18,19$;

- Usando conjuntos de objetos bidimensionais: 23, 24, 25, 29, 30, 31;

- Usando problemas orais: 26, 27, 28.

- Nas questões 32, 33 e 34 é trabalhado o reconhecimento de figuras geométricas.

\section{Coleta de dados e concordância entre observadores}

O aplicador apresentou os materiais e as instruções de acordo com a sequência do PRAHM, com o registro das respostas em uma ficha pelo próprio aplicador e por um segundo 
observador independente. Após a apresentação dos materiais e instrução, o participante tinha até 20 segundos para responder cada atividade. Caso o participante respondesse fora deste tempo, esta era considerada incorreta. Respostas diferentes daquelas especificadas na última coluna do PRAHM também eram consideradas incorretas.

A concordância entre os observadores foi analisada para cada participante e foi realizada para todas as sessões. Foram registradas todas as respostas dos participantes de forma independente por cada observador e depois elas foram comparadas para calcular o número de concordâncias (a mesma resposta foi registrada pelos dois observadores) e discordâncias (respostas diferentes foram registradas). Segundo Fagundes (1999), são considerados fidedignos se houver concordância de, no mínimo, $80 \%$, segundo a fórmula:

$$
\text { Concordâncias }=\frac{\left(\mathrm{N}^{\circ} \text { de Concordâncias }\right)}{\left(\mathrm{N}^{\mathrm{o}} \text { de Concordâncias }+\mathrm{N}^{\circ} \text { de Discordâncias }\right)} * 100
$$

Os cálculos indicaram 100\% de concordância entre os observadores.

\section{Consistência procedural}

O comportamento do aplicador na aplicação correta do instrumento foi avaliado por um observador que preencheu uma ficha com o registro desses comportamentos, como a apresentação das atividades de acordo com a sequência do protocolo, apresentação correta da instrução e dos materiais de cada atividade e ausência de dicas para os participantes, de acordo com a descrição de cada atividade do PRAHM.

\section{Resultados e discussão}

Foi registrado e analisado o número de acertos de cada participante no Protocolo de Registro e Avaliação das Habilidades Matemáticas (PRAHM) e em cada uma das habilidades matemáticas: habilidades pré-aritméticas (maior/ menor/ igual e mais/ menos), produção de sequência, habilidades de contagem, e reconhecimento de figuras geométricas.

Os 11 participantes com síndrome de Down tinham idade média de 7,7 anos, com seis participantes do gênero masculino e cinco do gênero feminino. Todos frequentavam instituições especializadas e dez deles estavam também matriculados em escolas regulares. O tempo médio de cada sessão para esses participantes foi de 13,5 minutos, sendo que a de menor duração foi de seis minutos e a de maior duração foi de 25 minutos. O desempenho desses participantes, em porcentagem de acertos, está apresentado na Tabela 1 , sendo que o número médio de acertos foi de 9,8 questões, variando de nenhum acerto a 32 acertos. 
Costa, A. B.; Picharillo, A. D. M.; Elias, N. C.

Tabela 1. Desempenho geral dos participantes com S. de Down

\begin{tabular}{lrrrrrrr}
\hline \multirow{2}{*}{ Participantes } & $\begin{array}{c}\text { Idade } \\
\text { (anos) }\end{array}$ & \multicolumn{2}{c}{ Acertos } & \multicolumn{3}{c}{ Acertos por Habilidade Matemática (\%) } \\
\cline { 2 - 8 } & & Total & $\%$ & Contagem & Sequências & $\begin{array}{c}\text { Pré- } \\
\text { aritmética }\end{array}$ & Geometria \\
\hline P1S & 8 & 17 & 50,0 & 42,90 & 0,00 & 60,00 & 100,00 \\
P2S & 7 & 14 & 41,2 & 71,40 & 100,00 & 25,00 & 33,30 \\
P3S & 9 & 10 & 29,4 & 57,10 & 100,00 & 10,00 & 33,30 \\
P4S & 6 & 0 & 0 & 0,00 & 0,00 & 0,00 & 0,00 \\
P5S & 6 & 0 & 0 & 0,00 & 0,00 & 0,00 & 0,00 \\
P6S & 10 & 0 & 0 & 0,00 & 0,00 & 0,00 & 0,00 \\
P7S & 10 & 7 & 20,6 & 14,20 & 0,00 & 15,00 & 100,00 \\
P8S & 8 & 15 & 44,1 & 14,20 & 33,30 & 55,00 & 100,00 \\
P9S & 5 & 32 & 94,1 & 71,40 & 100,00 & 100,00 & 100,00 \\
P10S & 6 & 11 & 32,4 & 0,00 & 0,00 & 35,00 & 100,00 \\
P11S & 10 & 2 & 5,9 & 0,00 & 33,30 & 0,00 & 33,30 \\
Média & 7,7 & 9,8 & 31,2 & 24,65 & 33,33 & 27,27 & 54,54 \\
\hline
\end{tabular}

Fonte: Elaborado pelos autores.

Conforme pode ser observado na Tabela 1, ao agrupar os participantes de acordo com desempenhos gerais similares, do maior para o menor, tem-se:

- Desempenho geral maior que 80\%: um participante (P9S);

- Desempenho geral entre 50\% e 80\%: um participante (P1S);

- Desempenho geral entre 30\% e 50\%: três participantes (P2S, P8S e P10);

- Desempenho geral entre 10\% e 30\%: dois participantes (P3S e P7S);

- Desempenho geral entre 0\% e 10\%: quatro participantes (P4S, P5S, P6S e P11S).

Nota-se que apenas dois participantes (18\% dos participantes) tiveram desempenho igual ou superior a $50 \%$ e que nove participantes $(82 \%)$ apresentaram desempenho abaixo de $50 \%$. Também se observa que não há relação entre idade e desempenho, sendo que o participante mais novo foi o que obteve melhor desempenho.

A Tabela 1 também apresenta os desempenhos de cada participante separados por categoria: habilidades pré-aritméticas (maior/ menor/ igual e mais/ menos), produção de sequência, habilidades de contagem e reconhecimento de figuras geométricas. De maneira geral, os participantes apresentaram 100\% de respostas corretas de nomeação de figuras geométricas (última coluna da Tabela 1), indicando que os outros repertórios não são pré-requisito para o repertório de nomeação. Entretanto, parece haver uma relação entre o repertório de contagem e os repertórios de sequência e pré-aritmético, ou seja, os participantes que não apresentaram repertório de contagem também não apresentaram repertório de sequência ou pré-aritmética (CARMO, 2012). Segundo Cornwell (1974), crianças com SD apresentam dificuldades na aquisição de contagem devido ao déficit na memória de curto prazo. As exceções foram P10S 
e P11S, que obtiveram 0\% de respostas corretas no repertório de contagem e obtiveram 35\% e 33,3\% de respostas corretas nos testes pré-aritméticos e de sequência, respectivamente.

Como pode ser observado, P9S foi o participante com SD com melhor desempenho: teve acerto de 32 respostas corretas das 34 questões (94,1\%). Os dois erros foram relativos a questões que envolviam contagem de fichas de papelão. O resultado desse participante indica um bom desempenho nas habilidades de produção de sequências, diferentemente do que foi encontrado por Chung e Tam (2005) e Malaquias et al. (2013). Por outro lado, os dois erros poderiam indicar dificuldades nos conceitos de contagem e numeração (RIETVELD, 2005). Nas questões referentes às habilidades pré-aritméticas, P9S acertou todas as questões, demonstrando conceitos de magnitude ou comparação de grandezas, mesmo com objetos unidimensionais. Este resultado indica que o participante tem as habilidades pré-aritméticas bem estabelecidas, conforme descritas por Carmo (2012). O participante também acertou todas as questões sobre o reconhecimento de figuras geométricas. No geral, os resultados sugerem que P9S tem os pré-requisitos para ser introduzido em habilidades matemáticas mais complexas, como soma, subtração, multiplicação, divisão e geometria plana e espacial (CARMO, 2012; LORENZATO, 1995).

$\mathrm{P} 1 \mathrm{~S}$ foi o participante com SD com segundo melhor desempenho (17 questões corretas). P1S acertou três das sete questões referentes à contagem e errou todas as questões referentes à produção de sequências. Este resultado mostra a dificuldade em estabelecer sequenciamento, corroborando com as afirmações de Chung e Tam (2005) e Malaquias et al. (2013), indicando problemas no aprendizado em princípios de contagem e numeração (RIETVELD, 2005). Sobre as questões referentes às habilidades pré-aritméticas, das 20 questões, o participante acertou $12(60 \%)$ nas atividades que envolviam objetos bidimensionais e tridimensionais. P1S também acertou todas as questões sobre o reconhecimento de figuras geométricas, replicando resultados de Zhou, Peverly e Lin (2005). Os erros do participante P1S podem também estar ligados a déficit nas habilidades de percepção e atenção, pois, conforme afirmam Chung e Tam (2005) e Malaquias et al. (2013), muitos alunos com deficiência intelectual têm dificuldade com as relações espaciais, distâncias e sequenciamento e podem apresentar problemas de atenção significativa e baixo nível de concentração em uma situação de aprendizagem formal, que podem interferir na aquisição de conceitos e habilidades matemáticas.

Os participantes P2S, P8S e P10S obtiveram desempenhos entre 30\% e 50\%. Apesar de apresentarem desempenhos percentuais gerais similares, esses participantes têm desempenho distinto em relação a cada categoria. Os resultados indicam que P2S tem requisitos nos conceitos de contagem, numeração e sequências, e que P8S e P10S apresentam conceitos de magnitude ou comparação de grandezas. Porém, os resultados indicam que P8S e P10S ainda não apresentam, de forma consistente, os conceitos de contagem, numeração e sequência e que P2S não tem o conceito de magnitude ou comparação de grandezas. Nas questões que envolviam reconhecimento de figuras geométricas, P8S e P10S acertaram todas as questões e P2S acertou somente uma, mostrando mais uma vez resultados distintos.

P3S e P7S tiveram desempenho geral entre $10 \%$ e 30\%, novamente com resultados distintos para cada categoria. De forma geral, os resultados de P3S e de P7S indicam que eles não têm os conceitos de contagem e numeração, conforme identificado em pesquisas anteriores com indivíduos com deficiência intelectual (CHUNG; TAM, 2005; MALAQUIAS et al. 2013; RIETVELD, 2005). Por outro lado, P3S acertou todas as questões nas atividades de sequência e P7S não acertou nenhuma, o que é condizente com o desempenho dos dois em contagem 
(CARMO, 2012). Os desempenhos dos dois participantes em habilidades pré-aritméticas foram baixos, indicando que os conceitos de magnitude ou comparação de grandezas não estão estabelecidos.

Finalmente, os quatro participantes restantes (P4S, P5S, P6S e P11S) obtiveram desempenho abaixo de $10 \%$ de respostas corretas. Vale ressaltar que esses participantes tinham pouca ou nenhuma linguagem oral, e grande dificuldade em seguir instruções, dificultando a aplicação do protocolo. Infere-se que os dois acertos de P11S foram ao acaso, pois não há outros indícios sinalizando algum domínio dessas habilidades. Para Abdelahmeed (2007) e Cornwell (1974), crianças com síndrome de Down com déficit de linguagem expressiva teriam maior dificuldade em tarefas de contar ou que necessitem de processamentos na memória de curto prazo. Além disso, Oliver e Buckley (1994) indicaram que existe uma grande diferença individual na aquisição de linguagem em crianças com $\mathrm{SD}$, e que o desenvolvimento de sua linguagem pode avançar em um ritmo mais lento do que em crianças com desenvolvimento típico, o que pode explicar os resultados mencionados anteriormente. Os resultados desses participantes indicam que a existência de alguns pré-requisitos é importante para a aplicação do protocolo e que o protocolo precisaria ser adaptado para atender indivíduos com déficit acentuados de linguagem.

Passando-se agora à análise dos resultados dos dez participantes com desenvolvimento típico, eles tinham idade média de 7,8 anos e todos estavam matriculados em escolas regulares. O tempo médio de cada sessão foi de 12,3 minutos, sendo que a de maior duração foi de 15 minutos e a menor foi de cinco minutos. Houve, então, uma pequena diferença em relação aos participantes com SD, cujo tempo médio de cada sessão foi de 13,5 minutos. A média de acertos desses participantes foi de 33,1 questões (97,4\% de respostas corretas), sendo que o mínimo foi de 29 e o máximo de 34 acertos, conforme pode ser visto na Tabela 2.

Tabela 2. Desempenho dos participantes com desenvolvimento típico

\begin{tabular}{lrrrrrrrr}
\hline Participantes & $\begin{array}{c}\text { Idade } \\
\text { (anos) }\end{array}$ & \multicolumn{2}{c}{ Acertos } & & Acertos por & Habilidade & $\begin{array}{c}\text { Matemática } \\
\text { (\%) }\end{array}$ \\
\cline { 3 - 8 } & & Total & \% & Contagem & Sequências & $\begin{array}{c}\text { Pré- } \\
\text { aritmética }\end{array}$ & Geometria \\
\hline P1T & 6 & 34 & 100,00 & 100 & 100 & 100 & 100 \\
P2T & 5 & 29 & 85,30 & 100 & 100 & 75 & 100 \\
P3T & 10 & 34 & 100,00 & 100 & 100 & 100 & 100 \\
P4T & 9 & 34 & 100,00 & 100 & 100 & 100 & 100 \\
P5T & 9 & 34 & 100,00 & 100 & 100 & 100 & 100 \\
P6T & 6 & 34 & 100,00 & 100 & 100 & 100 & 100 \\
P7T & 10 & 34 & 100,00 & 100 & 100 & 100 & 100 \\
P8T & 8 & 33 & 97,10 & 100 & 100 & 100 & 66,70 \\
P9T & 8 & 34 & 100,00 & 100 & 100 & 100 & 100 \\
P10T & 7 & 31 & 91,20 & 90 & 100 & 100 & 33,30 \\
Média & 7,8 & 33,1 & 97,40 & 99 & 100 & 98 & 90 \\
\hline
\end{tabular}

Fonte: Elaborado pelos autores. 
Avaliação de habilidades matemáticas em crianças com síndrome de Down ...

Esses resultados indicam uma grande diferença entre os participantes com SD (média de 31,2\% de respostas corretas) e os participantes com desenvolvimento típico (média de 97,4\% de respostas corretas) (BRANKAER; GHESQUIÈRE; DE SMEDT, 2011; RIETVELD, 2005). Esses resultados replicam, em certa medida, os achados de Brankaer, Ghesquière e De Smedt (2011), em que crianças com deficiência intelectual leve tiveram desempenho mais baixo que seus pares com desenvolvimento típico de mesma idade cronológica em tarefas que envolviam habilidades matemáticas.

Importante ressaltar que essa diferença pode não estar relacionada à deficiência intelectual ou outras comorbidades associadas aos participantes com SD, mas, sim, à história de vida desses participantes, principalmente, no que se refere ao tipo de atendimento especializado que eles recebem, às prioridades estabelecidas por professores, responsáveis ou cuidadores no que tange ao que eles devem aprender e, ainda, aos materiais e tecnologias de ensino empregadas nessa aprendizagem.

Conforme pode ser visto na Tabela 2, os participantes P1T, P3T, P4T, P5T, P6T, P7T e P9T acertaram todas as questões e P8T errou somente uma questão. O desempenho desses participantes indica domínio em todas as categorias testadas, indicando alto nível de compreensão de habilidades matemáticas elementares, confirmando resultados de outros estudos com indivíduos com desenvolvimento típico (BRANKAER; GHESQUIÈRE; DE SMEDT, 2011; ZHOU; PEVERLY; LIN, 2005). Segundo Carmo (2012) e Lorenzato (1995), esses resultados sugerem que esses participantes têm os pré-requisitos para serem introduzidos a habilidades matemáticas mais complexas, como soma, subtração, multiplicação, divisão e geometria plana e espacial.

P2T e P10T tiveram desempenho superior a 85\%. P10T errou três questões, sendo uma de contagem e duas de reconhecimento de figuras geométricas. Os cinco erros de P2T foram relativos ao grupo de questões sobre habilidades pré-aritméticas (um erro na comparação de conjuntos de objetos tridimensionais e quatro erros na comparação de conjuntos de objetos bidimensionais), indicando que o conceito de magnitude ou comparação de grandezas podem não estar bem estabelecido. Outros estudos (BRANKAER; GHESQUIÈRE; DE SMEDT, 2011; MALAQUIAS et al., 2013; ZHOU; PEVERLY; LIN, 2005) encontraram resultados semelhantes no que diz respeito a dificuldades em realizar tarefas com materiais bidimensionais, como figuras ou desenhos.

Diferentemente do que pode ser observado para os participantes com SD, o participante com desenvolvimento típico mais jovem (P2T) foi o que obteve desempenho mais baixo. Isso pode indicar que crianças com desenvolvimento típico que frequentem escolas regulares passam por um processo de aprendizagem de matemática de maneira bastante semelhante, de acordo com a série e matrizes curriculares melhor estabelecidas.

\section{Considerações finais}

A pesquisa avaliou satisfatoriamente o repertório das habilidades matemáticas de contagem e numeração, de produção de sequências, de habilidades pré-aritméticas e de reconhecimento de figuras geométricas, usando materiais discretos e contínuos, em crianças com síndrome de Down ou com desenvolvimento típico. 
Os resultados indicam claramente o desempenho mais baixo dos participantes com SD em comparação com aqueles com desenvolvimento típico (o desempenho dos participantes com $\mathrm{SD}$ foi de aproximadamente um terço do desempenho dos participantes com desenvolvimento típico), chega-se próximo aos resultados do estudo de Brankaer, Ghesquière e De Smedt (2011). Tal desempenho mais baixo pode estar ligado às dificuldades nas habilidades que requeiram atenção, memória, raciocínio e abstração, fundamentais para o aprendizado acadêmico em geral (CHUNG; TAM, 2005; MALAQUIAS et al., 2013).

De maneira geral, os participantes com SD tiveram melhor desempenho nas questões que envolviam geometria e manipulação de objetos tridimensionais, e os desempenhos mais baixos parecem estar relacionados com as habilidades pré-aritméticas, nas quais são testados conceitos de magnitude ou comparação de grandezas de objetos (maior, menor e igualdade) e com as habilidades de contagem, numeração e produção de sequências. De acordo com Carmo (2012), há uma forte relação entre repertórios de comparações de grandezas e os repertórios de contagem. Entre estes participantes, dois deles tiveram desempenho superior a $50 \%$, sendo que um deles com desempenho equivalente aos seus pares com desenvolvimento típico.

Os resultados dos participantes com desenvolvimento típico, com pouquíssimos erros, indicam que eles têm os pré-requisitos para serem introduzidos em habilidades matemáticas mais complexas (CARMO, 2012; LORENZATO, 1995). Os resultados desses participantes é um forte indício de que o PRAHM, desenvolvido pelos pesquisadores para esse estudo, pode ser uma importante ferramenta para avaliar os repertórios de matemática de crianças. Apesar dos desempenhos mais baixos dos participantes com SD, o protocolo mostrou-se aplicável também para crianças com Deficiência Intelectual, com exceção dos participantes com déficit severos de linguagem, indicando que o protocolo precisa de algumas adaptações para ter um alcance maior. Dessa maneira, o protocolo pode se constituir uma ferramenta importante, como ponto de partida para a realização do planejamento de ensino de conceitos matemáticos (CARMO, 2012).

Vale ressaltar que uma reformulação do protocolo poderia ser feita, colocando-se primeiro as questões relativas aos conceitos de habilidades pré-aritméticas, depois as questões relativas à numeração e produção de sequências, e em seguida contagem, conforme é mostrado por Carmo (2012) ao descrever um programa de ensino de repertório de habilidades matemáticas a pessoas com deficiência intelectual, a qual decorre de diversas experiências de aplicação de tecnologias de ensino. Outro possível efeito de sequência refere-se às questões de reconhecimento e nomeação de figuras geométricas (questões 32, 33 e 34) que são apresentadas após as questões de comparação de objetos bidimensionais (questões 14, 15 e 16), em que as instruções continham os nomes das formas geométricas, ou seja, a nomeação dos objetos na presença dos objetos pode ter gerado aprendizado durante as sessões de teste. 
Avaliação de habilidades matemáticas em crianças com síndrome de Down ...

\section{Referências}

ABDELAHMEED, H. Do children with Down Syndrome have difficulty in counting and why? International Journal of Special Education, Vancouver, v. 22, n. 2, p. 129-139, 2007. Disponível em: <http://files.eric.ed.gov/fulltext/EJ814496.pdf>. Acesso em: 20 dez. 2016.

AMERICAN PSYCHIATRIC ASSOCIATION. Intellectual disability fact sheet: DSM-5. Arlington, 2013.

BRANKAER, C.; GHESQUIÈRE, P.; DE SMEDT, B. The development of numerical magnitude processing and its association with working memory in children with mild intellectual disabilities. Research in Developmental Disabilities, Oxford, v. 34, n. 10, p. 3361-3371, 2013. Disponível em: <http://dx.doi.org/10.1016/j.ridd.2013.07.001>. Acesso em: 20 dez. 2016.

. Numerical magnitude processing in children with mild intellectual

disabilities. Research in Developmental Disabilities, Oxford, v. 32, n. 6, p. 2853-2859, 2011. Disponível em: <http://dx.doi.org/10.1016/j.ridd.2011.05.020>. Acesso em: 20 dez. 2016.

BRASIL. Ministério da Saúde. Diretrizes de atenção à pessoa com síndrome de Down. Brasília, 2012. Disponível em: < http:// sage.saude.gov.br/pdf/viverSemLimite/ler_pdf. php?file=Diretriz_Sindrome_de_Down_M>. Acesso em: 20 dez. 2016.

BRASIL. Lei no 12.796, de 4 de abril de 2013. Altera a Lei no 9.394, de 20 de dezembro de 1996, que estabelece as diretrizes e bases da educação nacional, para dispor sobre a formação dos profissionais da educação e dar outras providências. Diário Oficial da União, Brasilia, 5 abr. 2013. Seção 1, p. 1. Disponível em: <http://www.planalto.gov.br/ccivil_03/_ato20112014/2013/lei/112796.htm>. Acesso em: 20 dez. 2016.

CARMO, J. S. Aprendizagem de conceitos matemáticos em pessoas com deficiência intelectual. Revista de Deficiência Intelectual, São Paulo, v. 2, n. 3, p. 43-48, 2012.

CHUNG, K. K. H.; TAM, Y. H. Effects of cognitive-based instruction on mathematical problem solving by learners with mild intellectual disabilities. Journal of Intellectual and Developmental Disability, Abingdon, v. 30, n. 4, p. 207-216, 2005.

CORNWELL, A. C. Development of language, abstraction, and numerical concept formation in Down's syndrome children. American Journal of Mental Deficiency, Washington, v. 79, n. 2, p. 179-190, 1974.

CRUZ, P.; BERGAMASCHI, A.; REIS, M. L. M. De olho nas metas 2011: quarto relatório de monitoramento das 5 metas do todos pela educação. São Paulo: Moderna, 2012.

FAGUNDES, A. J. F. M. Definição, descrição e registro do comportamento. 12. ed. São Paulo: EDICON, 1999.

GUALBERTO, P. M. A.; ALOI, P. E.; CARMO, J. S. Avaliação de habilidades pré-aritméticas por meio de uma bateria de testes. Revista Brasileira de Análise do Comportamento, Brasília, v. 5, n. 2, p. 21-36, 2012. Disponível em: <http://dx.doi.org/10.18542/rebac. v5i2.928>. Acesso em: 20 dez. 2016. 
LORENZATO, S. Por que não ensinar geometria? Educação Matemática em Revista, Brasília, v. 3, n. 4, p. 4-13, 1995.

MALAQUIAS, F. F. O. et al. VirtualMat: a serious game to teach logical-mathematical concepts for students with intellectual disability. Technology and Disability, Amsterdam, v. 25, n. 2, p. 107-116, 2013. Disponível em: <https://doi.org/10.3233/TAD-130375>. Acesso em: 20 dez. 2016.

MURPHY, M. M. A review of mathematical learning disabilities in children with fragile X syndrome. Developmental Disabilities Research Reviews, Hoboken, v. 15, n. 1, p. 21-27, 2009. Disponível em: <https://doi.org/10.1002/ddrr.49>. Acesso em: 20 dez. 2016.

OLIVER, B.; BUCKLEY, S. The language development of children with Down's syndrome: first words to two-word phrases. Down Syndrome Research and Practice, Southsea, v. 2, n. 2, p. 71-75, 1994. Disponível em: < https://doi.org/10.3104/reports.33>. Acesso em: 20 dez. 2016.

RIETVELD, C. M. Classroom learning experiences of mathematics by new entrant children with Down syndrome. Journal of Intellectual and Developmental Disability, Abingdon, v. 30, n. 3, p. 127-138, 2005.

ROSENBLUM, L. P.; HERZBERG, T. Accuracy and techniques in the preparation of mathematics worksheets for tactile learners. Journal of Visual Impairment and Blindness, New York, v. 105, n. 7, 402-413, 2011.

ROSSIT, R. A. S. Matemática para deficientes mentais: contribuições do paradigma de equivalência de estímulos para o desenvolvimento e avaliação de um currículo. 2003. 180 f. Tese (Doutorado em Educação Especial) - Universidade Federal de São Carlos, São Carlos, 2003.

YOKOYAMA, L. A. Uma abordagem multissensorial para o desenvolvimento do conceito de número natural em indivíduos com síndrome de Down. 2012. 228 f. Tese (Doutorado em Educação Matemática) - Universidade Bandeirante de São Paulo, São Paulo, 2012.

ZHOU, Z.; PEVERLY, S. T.; LIN, J. Understanding early mathematical competencies in American and Chinese children. School Psychology International, London, v. 26, n. 4, p. 413-427, 2005.

Artigo recebido em 23/07/2015. Aceito em 03/08/2016.

Endereço para contato: Rua Durvalino Gonçalves da Silva, 892, V. S. João Batista, CEP 13567-000, São Carlos, SP, Brasil. 